\title{
Evaluation of hepatic biotransformation of polybrominated diphenyl ethers in the polar bear (Ursus maritimus)
}

Lisa K. Krieger ${ }^{\mathrm{a}}$, András Szeitz ${ }^{\mathrm{a}}$ and Stelvio M. Bandiera ${ }^{\mathrm{a}}$

${ }^{a}$ Faculty of Pharmaceutical Sciences, The University of British Columbia, Vancouver, British Columbia, Canada V6T 1 Z3

Corresponding author:

Stelvio M. Bandiera, Faculty of Pharmaceutical Sciences, The University of British Columbia, 2405 Wesbrook Mall, Vancouver, British Columbia, Canada V6T 1Z3

Tel. +01-604-822-3815. E-mail: $\underline{\text { bandiera@ mail.ubc.ca }}$ 


\section{ABSTRACT}

Polar bears are at the top of the Arctic marine food chain and are subject to exposure and bioaccumulation of environmental chemicals of concern such as polybrominated diphenyl ethers (PBDEs), which were widely used as flame-retardants. The aim of the present study was to evaluate the in vitro oxidative metabolism of 2,2',4,4'-tetrabrominated diphenyl ether (BDE-47) and 2,2',4,4',5-pentabrominated diphenyl ether (BDE-99) by polar bear liver microsomes. The identification and quantification of the hydroxy-brominated diphenyl ethers formed were assessed using an ultra-high performance liquid chromatography-tandem mass spectrometrybased method. Incubation of BDE-47 with archived individual liver microsomes, prepared from fifteen polar bears from northern Canada, produced a total of eleven hydroxylated metabolites, eight of which were identified using authentic standards. The major metabolites were $4^{\prime}-$ hydroxy-2,2',4,5'-tetrabromodiphenyl ether and 5'-hydroxy-2,2',4,4'-tetrabromodiphenyl ether. Incubation of BDE-99 with polar bear liver microsomes produced a total of eleven hydroxylated metabolites, seven of which were identified using authentic standards. The major metabolites were 2,4,5-tribromophenol and 4-hydroxy-2,2',3,4',5-pentabromodiphenyl ether. Among the CYP specific antibodies tested, anti-rat CYP2B was found to be the most active in inhibiting the formation of hydroxylated metabolites of both BDE-47 and BDE-99, indicating that CYP2B was the major CYP enzyme involved in the oxidative biotransformation of these two congeners. Our study shows that polar bears are capable of forming multiple hydroxylated metabolites of BDE47 and BDE-99 in vitro and demonstrates the role of CYP2B in the biotransformation and possibly in the toxicity of BDE-47 and BDE-99 in polar bears. 
Keywords:

Polybrominated diphenyl ether, BDE-47, BDE-99, polar bear, liver, oxidative biotransformation, hydroxylated metabolites, UHPLC/MS/MS 


\section{Introduction}

Polybrominated diphenyl ethers (PBDEs) are man-made chemicals that were used as additive flame retardants in a variety of industrial and commercial products including textiles, polyurethane foam and plastics. PBDEs were formulated as commercial mixtures known as PentaBDE, OctaBDE and DecaBDE, according to their average bromine content (La Guardia et al., 2006). The PentaBDE mixture, which was used extensively in North America, was composed predominantly of 2,2',4,4'-tetrabromodiphenyl ether (BDE-47) and 2,2',4,4',5pentabromodiphenyl ether (BDE-99) (Alaee et al., 2003). Because PBDEs were not chemically bound to polymers used in the manufacture of these products, they can migrate out of products during use or after disposal and can be released into the environment. As a consequence, PBDEs have become widespread environmental pollutants (Hites, 2004; Law et al., 2014). BDE-47 and BDE-99, for example, have been detected in household dust, indoor air, fish, marine mammals, and in human blood, breast milk and adipose tissue, and are frequently the dominant PBDE congeners found in these samples (Hale et al., 2001; Stapleton et al., 2005; Gomara et al., 2007; Sjodin et al., 2008; Daniels et al., 2010; Gewurtz et al., 2011; Quiros-Alcala et al., 2011; Besis and Samara, 2012; Rotander et al., 2012). Production of the PentaBDE and OctaBDE mixtures was banned in the European Union in 2004 and discontinued in North America due to concerns about the persistence and bioaccumulation of PBDEs. The PentaBDE and OctaBDE mixtures were added to the Stockholm Convention on Persistent Organic Pollutants in 2009.

The occurrence of PBDEs in the Arctic has been documented extensively with several studies suggesting that long-range transport from more southerly locations is likely the main source of these contaminants (Ikonomou et al., 2002; de Wit et al., 2006; Kelly et al., 2008; McKinney et al., 2010; Dietz et al., 2013). PBDEs have been measured in arctic biota including fish seabirds, seals, whales and polar bears (de Wit et al., 2006; de Wit et al., 2010; Letcher et 
al., 2010; Dietz et al., 2013). Polar bears (Ursus maritimus) are distributed throughout the arctic circumpolar regions and occupy a high trophic position in the Arctic marine food chain. They feed on ringed seals (Phoca hispida), other seal species and other marine mammals such as bowhead whales (Balena mysticetus) (McKinney et al., 2013; McKinney et al., 2015) and have a diet high in fat, which tends to accumulate lipophilic compounds such as PBDEs. Surveys of temporal contaminant trends in polar bears from eastern Greenland and western Hudson Bay showed that total PBDE concentrations in liver or adipose tissue increased steadily from the 1980s until the mid-2000s, after which levels have started to decline (McKinney et al., 2010; Dietz et al., 2013). The dominant congeners detected in adipose tissue from polar bears were BDE-47, BDE-99, 2,2',4,4',6-pentabromodiphenyl ether (BDE-100) and 2,2',4,4',5,5'hexabromodiphenyl ether (BDE-153), whereas BDE-47 and BDE-99 were the major congeners found in ringed seal blubber (de Wit et al., 2010). The toxicity of PBDEs in polar bears is unknown, but studies with laboratory animals have shown that developmental exposure to BDE47 or BDE-99, at relatively high dosages, caused neurobehavioural disturbances and alterations in neuromotor activity (Branchi et al., 2003; Gee and Moser, 2008; Cheng et al., 2009; Kodavanti et al., 2015), changes to the reproductive system (Kuriyama et al., 2005; Lilienthal et al., 2006; Talsness et al., 2008) and disruption of thyroid hormone activity (Hallgren et al., 2001; Zhou et al., 2001; Talsness et al., 2008; Kodavanti et al., 2010).

Oxidative metabolism of BDE-47 and BDE-99 has been investigated in laboratory animals and, more recently, in humans (Erratico et al., 2011; Erratico et al., 2012, 2013; Feo et al., 2013). In vitro studies revealed that BDE-47 and BDE-99 are metabolized by hepatic cytochrome P450 (CYP) enzymes to multiple hydroxylated metabolites. Evidence of PBDE metabolism by wildlife species, especially arctic marine mammals, is limited. Letcher and co- 
workers investigated the biotransformation of various classes of persistent organic pollutants including PBDEs by polar bear liver microsomes in vitro and found little, if any, depletion of PBDE substrates (Letcher et al., 2009). In a later study, they assessed oxidative metabolism of selected PBDE congeners using liver microsomes from a polar bear and two other arctic marine species and detected a single hydroxylated metabolite of $2,2^{\prime}, 4,4^{\prime}, 5,6^{\prime}$-hexabromodiphenyl ether (BDE-154) only, indicating minimal hepatic PBDE metabolism by polar bears (McKinney et al., 2011). However, hydroxy-brominated diphenyl ethers (OH-BDEs) have been identified in plasma and adipose tissue samples from polar bears from Norway (Verreault et al., 2005), Greenland (Gebbink et al., 2008) and Canada (Chu and Letcher, 2013). OH-BDEs have also been detected in beluga whales and ringed seals (McKinney et al., 2006; Routti et al., 2009). OH-BDEs have been reported to occur as natural products in the marine environment (Malmvarn et al., 2008). Thus, dietary exposure via the food chain could be the source of the OH-BDEs detected in polar bears. An alternative explanation is that the OH-BDEs are products of in vivo biotransformation of PBDEs in polar bear liver. To address the question of whether polar bears are capable of producing OH-BDE metabolites, a more thorough assessment of the oxidative metabolism of PBDEs by polar bears is needed. The aim of the present study was to evaluate hepatic biotransformation of PBDEs by polar bears. Previously prepared (archived) liver microsomes from 15 individual polar bears were incubated with BDE-47 or BDE-99 and the formation of hydroxylated metabolites was measured by ultra-high performance liquid chromatography-tandem mass spectrometry (UHPLC/MS/MS). In addition, antibody inhibition experiments were conducted to determine the CYP enzymes involved in metabolite formation.

\section{Materials and methods}




\subsection{Chemicals and reagents}

BDE-47 (neat, 100\% purity), BDE-99 (neat, $\geq 99.2 \%$ purity), 2,4,5-tribromophenol (2,4,5-TBP), 4'-hydroxy-2,2',4,6-tetrachlorobiphenyl (4'-OH-CB-50; neat, 99.9\% purity), 4hydroxy-2,3',4,5',6-pentachlorobiphenyl (4-OH-CB-121; neat, 99.9\% purity) and OH-BDEs, including 3'-hydroxy-2,4,4'-tribromodiphenyl ether (3'-OH-BDE-28), were purchased from AccuStandard (New Haven, CT, USA), as reported previously (Erratico et al., 2012, 2013). 2 Hydroxy-2',3,4,4',5-pentabromodiphenyl ether (2-OH-BDE-123) was a generous gift from Dr. R.J. Letcher (Environment Canada, Ottawa, ON, Canada). (Note: a list of the OH-BDEs analyzed in the present study, along with their substitution pattern, is found in the Supplementary material section). NADPH, sucrose and 2,4-dibromophenol (2,4-DBP) were purchased from Sigma Aldrich (Oakville, ON, Canada). Methanol, acetonitrile, methyl-tert-butyl ether, hexanes, isopropanol (all HPLC grade), hydrochloric acid and sodium hydroxide were purchased from Fisher Scientific (Ottawa, ON, Canada). Formic acid (puriss. p.a. for mass spectroscopy) was from Fluka (Steinheim, Germany). Ultrapure water was prepared using a Millipore Milli-Q system (Millipore, Billerica, MA, USA). Rabbit polyspecific anti-rat CYP1A IgG, anti-rat CYP2B IgG, anti-rat CYP2C IgG and anti-CYP3A IgG were prepared in S. Bandiera's laboratory and the specificity of each antibody was assessed by immunoblot analysis with purified or recombinant rat CYP enzymes and with various liver microsomal preparations, as described previously (Wong and Bandiera, 1996; Anderson et al., 1998; Hrycay and Bandiera, 2003).

\subsection{Calibration standards}

A calibration mixture consisting of hydroxy-tribromodiphenyl ethers (OH-triBDEs), hydroxy-tetrabromodiphenyl ethers (OH-tetraBDEs) and 2,4-DBP, at a range of concentrations, 
along with an internal standard (4'-OH-CB-50, at a single concentration of $1.25 \mu \mathrm{M}$ ), was prepared for the identification of the hydroxylated metabolites of BDE-47, as described previously (Erratico et al., 2013). A second calibration mixture consisting of OH-triBDEs, OHtetraBDEs, hydroxy-pentabromodiphenyl ethers (OH-pentaBDEs), 2,4-DBP and 2,4,5-TBP, at a range of concentrations, along with an internal standard (4-OH-CB-121, at a single concentration of $0.5 \mu \mathrm{M}$ ) was prepared for the identification of the hydroxylated metabolites of BDE-99, as described previously (Erratico et al., 2012). Final concentrations of the metabolite standards in the calibration mixtures were $2.5,5,10,25,50$ and $100 \mathrm{nM}$.

\subsection{Polar bear liver microsomes}

Hepatic microsomes were previously prepared from sixteen individual adult male polar bears. Fifteen of the polar bear liver samples were collected from bears that were killed in legally controlled hunts by Inuit near Resolute (Nunavut Territory, Canada) in April 1992, April 1993 and April 1994. The sixteenth liver sample was from a polar bear killed near Churchill (MN, Canada) in November 1993. The hepatic microsomes have been stored at $-80{ }^{\circ} \mathrm{C}$ at the University of British Columbia (Vancouver, BC, Canada). Details about the collection and preparation of the polar bear liver samples were reported previously (Bandiera et al., 1995; Letcher et al., 1996). Of the sixteen polar bear hepatic microsomal fractions that had been prepared, one sample, collected in April 1992, was not used in the current study due to the small volume of hepatic microsomes remaining.

\subsection{BDE-47 and BDE-99 biotransformation assays}


The in vitro biotransformation assays for BDE-47 and BDE-99 were performed as previously reported (Erratico et al., 2012, 2013), with the following modification. Reaction mixtures (1 mL, final volume) containing BDE-47 or BDE-99 (100 $\mu \mathrm{M}$, final concentration), polar bear hepatic microsomes $(1 \mathrm{mg} \mathrm{mL}-1$, final concentration) and NADPH (1 mM, final concentration) in $50 \mathrm{mM}$ potassium phosphate buffer with $3 \mathrm{mM}$ magnesium chloride (pH 7.4), were incubated for $20 \mathrm{~min}$. The reaction was stopped by addition of $1.0 \mathrm{~mL}$ of ice-cold $0.5 \mathrm{M}$ sodium hydroxide. The reaction mixtures were processed and analyzed as described previously (Erratico et al., 2012, 2013). Biotransformation assays with BDE-47 and BDE-99 were performed separately with 15 individual polar bear liver microsomes and three or more independent experiments were conducted with each substrate and each microsomal preparation.

Preliminary experiments were conducted using polar bear liver microsomes to determine the linearity of product formation with respect to incubation time and hepatic microsomal protein concentration. Blank and control samples in which substrate (BDE-47 or BDE-99), hepatic microsomes, or NADPH was omitted from the reaction mixture were routinely included in each assay. Peaks corresponding to OH-BDEs were not detected when BDE-47 or BDE-99 was omitted from the reaction mixtures, indicating that $\mathrm{OH}-\mathrm{BDEs}$ were not present in the microsomal preparations. However, a peak corresponding to 2,4-DBP was detected in control samples that contained polar bear liver microsomes but not substrate, indicating that 2,4-DBP was either a contaminant in the microsomal preparations or that another compound, which generated a coeluting peak, was present in the microsomal preparations.

\subsection{Antibody inhibition experiments}


To evaluate the contribution of CYP1A, CYP2B, CYP2C or CYP3A enzymes on metabolite formation, reaction mixtures containing polar bear hepatic microsomes $(1 \mathrm{mg} \mathrm{mL}-1$, final concentration) and $50 \mathrm{mM}$ potassium phosphate buffer with $3 \mathrm{mM}$ magnesium chloride (pH 7.4) were preincubated for $10 \mathrm{~min}$ at $37{ }^{\circ} \mathrm{C}$ with various amounts of rabbit anti-rat CYP1A, CYP2B, CYP2C or CYP3A IgG. BDE-47 or BDE-99 (100 $\mu \mathrm{M}$, final concentration) was then added. The reaction was initiated by addition of NADPH, allowed to proceed for 20 min, and stopped by addition of $1.0 \mathrm{~mL}$ of ice-cold $0.5 \mathrm{M}$ sodium hydroxide. The reaction mixtures were processed and analyzed as described previously (Erratico et al., 2011; Erratico et al., 2012). Due to the limited supply of some antibodies, antibody inhibition experiments involving BDE-47 or BDE-99 were performed with liver microsomes from two polar bears only.

\subsection{Analytical method}

UHPLC/MS/MS was used to resolve and quantify hydroxylated metabolites of BDE-47 as reported previously (Moffatt et al., 2011; Erratico et al., 2013), with the following modifications. The column temperature was maintained at $40{ }^{\circ} \mathrm{C}$ and the autosampler tray temperature was $10{ }^{\circ} \mathrm{C}$. Solvent A consisted of water with $0.1 \%$ formic acid (FA) and solvent B was a mixture of $25 \%$ acetonitrile, $75 \%$ methanol and $0.1 \%$ FA. An isocratic mobile phase consisting of $35 \%$ solvent $\mathrm{A}$ and $65 \%$ solvent $\mathrm{B}$, with a flow rate of $0.2 \mathrm{~mL}$ min- 1 , and a run time of 60 min was used. The mobile phase flow was diverted to waste during the first three minutes and was then switched to the mass spectrometer until the end of the chromatographic run. Analytes were monitored using the total ion current (TIC) of the multiple reaction monitoring (MRM) transitions in negative ionization mode. The mass spectrometric parameters were as follows: nitrogen gas was used for the curtain gas, collision gas and ion source gas 2 
(vaporizing gas); zero air was used for ion source gas 1 (nebulizing gas); the entrance potential was -10 units; resolution was Q1 Unit, Q3 Unit; and dwell time was $250 \mathrm{msec}$ for all compounds. Curtain gas was 30 units, collision gas (CAD) was medium, temperature was 400 ${ }^{\circ} \mathrm{C}$, ion source gas 1 was 30 units, ion source gas 2 was 60 units, ion spray voltage was $-4500 \mathrm{~V}$. Representative chromatograms showing $\mathrm{m} / \mathrm{z}$ values and retention times of BDE-47 authentic metabolite standards are presented in the Supplementary material section, Fig. S1.

Hydroxylated metabolites of BDE-99 were resolved and quantified by UHPLC/MS/MS as reported previously (Erratico et al., 2010, 2012), with the following modifications. Solvent A consisted of water with $0.1 \% \mathrm{FA}$ and solvent $\mathrm{B}$ was a mixture of $33 \%$ acetonitrile, $67 \%$ methanol and $0.1 \%$ FA. Gradient elution with the following profile was used. Solvent A:solvent B (35:65, v/v) from 0 to 55 min followed by a linear increase to solvent A:solvent B $(30: 70, v / v)$ from 55 to $58 \mathrm{~min}$, maintained at solvent A:solvent B $(30: 70$, v/v) from 58 to $82 \mathrm{~min}$, then the column was re-equilibrated with solvent A:solvent B (35:65, v/v) from 82.1 to $85 \mathrm{~min}$. The flow rate was $0.2 \mathrm{~mL}$ min- 1 and the total run time $85 \mathrm{~min}$. The mobile phase flow was diverted to waste during the first three minutes and was then switched to the mass spectrometer until the end of the chromatographic run. Analytes were monitored using the TIC of the MRM transitions in negative ionization mode. The mass spectrometric parameters were the same as outlined above, except that the curtain gas was 20 units, temperature was $450{ }^{\circ} \mathrm{C}$, and ion source gas 1 was 40 units. Representative chromatograms showing $\mathrm{m} / \mathrm{z}$ values and retention times of BDE-99 authentic metabolite standards are presented in the Supplementary material section, Fig. S2.

Additional details about method performance are reported in the Supplementary material section. 


\section{Results}

\subsection{Oxidative biotransformation of BDE-47}

Incubation of polar bear liver microsomes with BDE-47 yielded eleven metabolites (Fig. 1). Formation of OH-BDE metabolites was not observed when microsomal protein, BDE-47 or NADPH was omitted from the incubation mixture. Eight of the metabolites were identified by comparison of multiple reaction monitoring (MRM) transition values and retention times with those of authentic standards. The known metabolites, in order of elution, were 2,4-DBP, 3'-OHBDE-28, 4'-OH-BDE-17, 2'-OH-BDE-28, 4-OH-BDE-42, 5-OH-BDE-47, 4'-OH-BDE-49 and 6OH-BDE-47. Three metabolites labeled as A, B and C were not identified because their retention times did not match with any of the authentic standards (Fig. 1). Formation of 3-OH-BDE-47 was investigated but was not detected.

Formation rates were measured, where possible, for individual metabolites with each of the polar bear liver microsome preparations, using a protein concentration of $1 \mathrm{mg} \mathrm{mL}-1$, a BDE47 concentration of $100 \mu \mathrm{M}$ and an incubation time of $20 \mathrm{~min}$. All eleven metabolites were produced by each of the fifteen liver preparations, but the amounts of each metabolite formed differed among the polar bear samples and some metabolites were below the limit of quantification. On the basis of mean rates of formation, the major known metabolites were 4'OH-BDE-49, 5-OH-BDE-47, 3'-OH-BDE-28 and 6-OH-BDE-47, while 4-OH-BDE-42, 4'-OHBDE-17 and 2'-OH-BDE-28 were minor metabolites (Table 1). Formation of 2,4-DBP was not quantified, despite an observed time- and protein-dependent increase in the level of 2,4-DBP, due to interference from a co-eluting peak arising from the polar bear liver microsomes.

Unknown metabolite A exhibited MRM transition values that would be expected of a dihydroxy-tetrabrominated diphenyl ether (diOH-tetraBDE) (Fig. 1B). A peak with the same 
short retention time as A (appox. $11 \mathrm{~min}$ ), but with MRM transition values corresponding to monoOH-tetraBDE, was also detected on the chromatograms (Fig. 1A). It was concluded that the two peaks were likely the same metabolite and that the peak observed in Fig. 1A was a product of in-source fragmentation of the diOH-tetraBDE metabolite. The MRM transition values of unknown metabolites B and C correspond to monoOH-tetraBDEs (Fig. 1A). On the basis of peak area and response values, metabolite $\mathrm{B}$ was determined to be the major unknown metabolite formed by polar bear liver microsomes (Table 2).

\subsection{Oxidative biotransformation of BDE-99}

Incubation of BDE-99 with liver microsomes prepared from individual polar bears yielded eleven metabolites (Fig. 2). Formation of OH-BDE metabolites was not observed with incubation mixtures that were devoid of substrate, NADPH or microsomal protein. Seven metabolites were identified by comparison of MRM transition values and retention times with those of authentic standards. The known metabolites, in order of elution, were 2,4-DBP, 2,4,5TBP，4-OH-BDE-90，2-OH-BDE-123，5'-OH-BDE-99，6'-OH-BDE-99 and 4'-OH-BDE-101 (Fig. 2). On the basis of mean rates of formation, the major known metabolites were 2,4,5-TBP and 4-OH-BDE-90, whereas 5'-OH-BDE-99, 4'-OH-BDE-101 and 6'-OH-BDE-99 were minor metabolites (Table 3). 2,4-DBP could not be reliably quantified due to interference from a coeluting peak arising from the polar bear liver microsomes and 2-OH-BDE-123 was formed at less than quantifiable levels.

Four metabolites labeled as D, E, F and G could not be identified because their retention times did not match those of authentic standards. Unknown metabolite D exhibited MRM transition values and a short retention time suggestive of a dihydroxy-pentabrominated diphenyl 
ether (diOH-pentaBDE) (Fig. 2B). A peak with the same short retention time as D (appox. 16.4 min), but with MRM transition values corresponding to monoOH-pentaBDE, was observed in the chromatograms (Fig. 2A). As discussed above, this peak was not considered to be a new metabolite but was thought to be a product of in-source fragmentation of the diOH-pentaBDE metabolite. Unknown metabolites $\mathrm{E}, \mathrm{F}$ and $\mathrm{G}$ are likely to be monoOH-pentaBDEs because they exhibited MRM transition values that correspond to monoOH-pentaBDEs. On the basis of peak area and response values, metabolite $\mathrm{G}$ was determined to be the major unknown metabolite of BDE-99 (Table 4).

In addition, formation of monoOH-triBDEs and monoOH-tetraBDEs, including 3'-OHBDE-28, 4'-OH-BDE-17, 2'-OH-BDE-28, unknown metabolite B, 4-OH-BDE-42, 5-OH-BDE47, 4'-OH-BDE-49 and 6-OH-BDE-47, were observed following incubation of BDE-99 with some of the more catalytically active polar bear liver microsomal samples (4 out of 15) (Table 5 and Supplementary material, Fig. S3). A new unknown monoOH-tetraBDE metabolite, labeled H, was also detected among these metabolites (Supplementary material, Fig. S3C).

\subsection{Antibody inhibition}

The contribution of different CYP enzymes to BDE-47 and BDE-99 biotransformation was assessed separately in two different polar bear liver microsomal preparations using antibodies prepared against rat CYP1A, CYP2B, CYP2C and CYP3A enzymes. Anti-rat CYP2B IgG was found to be the most inhibitory of the antibodies tested towards formation of the metabolites of BDE-47. At a concentration of $2.5 \mathrm{mg} \operatorname{IgG} \mathrm{mg}-1$ microsomal protein, anti-rat CYP2B IgG decreased formation of 4'-OH-BDE-17, 2'-OH-BDE-28, 4-OH-BDE-42, 5-OHBDE-47, 4'-OH-BDE-49 and 6-OH-BDE-47 by 80-90\%. In comparison, anti-rat CYP1A, anti-rat 
CYP2C or anti-rat CYP3A decreased formation of some, but not all, metabolites to a maximum of $40 \%$.

A similar result was obtained with regard to BDE-99 biotransformation. Formation of 2,4,5-TBP, 4-OH-BDE-90, 5'-OH-BDE-99 and 6'-OH-BDE-99 were decreased by 70-86\% in the presence of anti-rat CYP2B IgG, at a concentration of $2.5 \mathrm{mg} \mathrm{IgG} \mathrm{mg-1} \mathrm{microsomal} \mathrm{protein,} \mathrm{and}$ by less than $40 \%$ in the presence of anti-rat CYP1A, anti-rat CYP2C or anti-rat CYP3A. In contrast, formation of 4'-OH-BDE-101 and unknown metabolites $F$ and $\mathrm{G}$ were inhibited to a greater extent by anti-rat CYP1A IgG than by anti-rat CYP2B IgG.

\section{Discussion}

The in vitro biotransformation of two PBDE congeners was evaluated using archived liver microsomes from fifteen polar bears. Eleven metabolites were observed when polar bear liver microsomes were incubated with BDE-47 and an additional eleven metabolites were observed when polar bear liver microsomes were incubated with BDE-99. The metabolites of BDE-47 included monoOH-triBDEs, monoOH-tetraBDEs and a diOH-tetraBDE. The BDE-99 metabolites, which were detected with all fifteen polar bear samples, included tribromophenol, monoOH-pentaBDEs and a diOH-pentaBDE. In addition, monoOH-triBDEs and monoOHtetraBDEs were detected as metabolites of BDE-99 with a subset of the more catalytically active polar bear samples.

Of the four major BDE-47 metabolites detected, two metabolites (5-OH-BDE-47 and 6OH-BDE-47) were produced by direct hydroxylation at an unsubstituted carbon atom, one metabolite (4'-OH-BDE-49) was formed by hydroxylation via a NIH shift mechanism and one metabolite (3'-OH-BDE-28) was produced through oxidative debromination. Of the three major 
metabolites of BDE-99, one metabolite (5'-OH-BDE-99) was produced by direct hydroxylation, one metabolite (4-OH-BDE-90) was produced by hydroxylation via a NIH shift mechanism and the most abundant metabolite (2,4,5-TBP) was formed by oxidative dealkyation. Clearly, oxidative dealkylation is a more important mechanism for the biotransformation of BDE-99 than BDE-47 by polar bear liver microsomes as oxidative dealkylation of BDE-47 results in the formation of 2,4-DBP, which was a minor metabolite of BDE-47.

The variety and pattern of metabolites produced indicates that hepatic biotransformation of BDE-47 and BDE-99 by polar bear is versatile and includes aromatic hydroxylation, oxidative debromination, dealkylation and dihydroxylation reactions. Similar versatility was observed in studies involving biotransformation of BDE-47 and BDE-99 by human and rat liver microsomes (Hamers et al., 2008; Dong et al., 2010; Erratico et al., 2011; Erratico et al., 2012, 2013; Feo et al., 2013). Among the antibodies tested, anti-rat CYP2B displayed the greatest inhibitory effect toward formation of BDE-47 and BDE-99 metabolites, suggesting that polar bear CYP2B enzymes were more active in catalyzing the oxidative biotransformation of BDE-47 and BDE-99 than CYP1A, CYP2C or CYP3A enzymes. Antibodies prepared against rat CYP enzymes were previously used to partially characterize the CYP composition of polar bear liver (Bandiera et al., 1995). On the basis of immunoblot results, it was determined that polar bear liver contains CYP enzymes that are immunochemically related to rat CYP1A1, CYP1A2, CYP2B, CYP3A and CYP2C enzymes (Bandiera et al., 1995) and that immunoreactive CYP2B protein levels appeared to be greater than CYP1A protein levels in these same polar bear liver microsomal preparations (Letcher et al., 1996). CYP2B6, which accounts for 1-7\% of total hepatic CYP content in humans (Ekins et al., 1998), was found to be the predominant enzyme catalyzing the oxidative biotransformation of BDE-47 and BDE-99 to multiple metabolites by human liver 
microsomes (Erratico et al., 2012, 2013; Feo et al., 2013). In contrast, experiments with recombinant rat CYP enzymes demonstrated that several enzymes including CYP1A, CYP2A, CYP2B, CYP2C and CYP3A contributed to the oxidative biotransformation of BDE-47 and BDE-99 by rat liver microsomes (Erratico et al., 2011).

Comparison of BDE-47 and BDE-99 biotransformation by polar bear liver microsomes and human liver microsomes revealed several similarities and some differences. For example, three of the major metabolites of BDE-47 produced by human liver microsomes (namely, 4'-OHBDE-49, 5-OH-BDE-47 and 6-OH-BDE-47) and were also major metabolites in polar bear liver microsomes. Likewise, 2,4,5-TBP was a major metabolite of BDE-99 in human and in polar bear liver microsomes and 3-OH-BDE-47, which is a major metabolite of BDE-47 in rodents (Hamers et al., 2008; Marsh et al., 2006), was not produced at detectable levels by either human or polar bear liver microsomes (Erratico et al., 2011). In contrast, 3'-OH-BDE-28 was a major metabolite of BDE-47 in polar bear liver microsomes, but was not produced by human liver microsomes (Erratico et al., 2013; Feo et al., 2013). Furthermore, 4-OH-BDE-90 was a major metabolite of BDE-99 in polar bear liver microsomes and was a minor metabolite in human liver microsomes, whereas 4'-OH-BDE-101, which was major metabolite in human liver microsomes, was a minor metabolite in polar bear liver microsomes (Erratico et al., 2012).

Oxidative metabolism of BDE-47 and BDE-99 by polar bear was relatively slow with maximal rates of formation for individual metabolites of approximately 2 to 3 pmol min-1 mg-1. In comparison, rates of formation of individual metabolites were 10 times greater with human liver microsomes (Erratico et al., 2012, 2013) and 10 to 100 times greater with liver microsomes prepared from rats that were treated with CYP inducers (Erratico et al., 2011). Whether the rates would be greater if freshly-prepared polar bear liver microsomes were used is unknown. The 
total CYP content of the polar bear liver microsomes used for the present study was previously shown to be similar to the total CYP content typically measured in rat liver microsomes (Bandiera et al., 1995; Letcher et al., 1996). Moreover, CYP-mediated activities, including alkoxyresorufin $O$-dealkylase and testosterone hydroxylase, were easily measurable in the polar bear liver microsomes (Bandiera et al., 1995; Letcher et al., 1996), indicating that the hepatic preparations were catalytically active. Letcher and co-workers used a duplicate set of archived liver microsomes from the same polar bears to assess PBDE biotransformation by measuring substrate depletion and found that biotransformation of the nine PBDE congeners tested, including BDE-47 and BDE-99, was very slow (Letcher et al., 2009). A similar result was obtained by McKinney and co-workers using liver microsomes prepared from fresh polar bear tissue samples. They were unable to find any metabolites of BDE-99 although a hydroxymetabolite of BDE-154 was detected with an in vitro biotransformation assay (McKinney et al., 2011). Thus, the present study is the first to show formation of multiple hydroxy-metabolites of PBDE congeners by polar bear liver samples.

The BDE-47 metabolites quantified in the present study are consistent with two studies that identified OH-BDEs in polar bears. Verrault et al. (2005) detected 4-OH-BDE-42 and 4'OH-BDE-49 in plasma, while Gebbink et al. (2008) detected low levels of 3-OH-BDE-47 in blood and 6-OH-BDE-47 in adipose tissue collected from polar bears (Verreault et al., 2005; Gebbink et al., 2008). Our analysis showing that 4-OH-BDE-42, 4'-OH-BDE-49 and 6-OHBDE-47 are metabolites of BDE-47 (and also minor metabolites of BDE-99) in polar bear liver microsomes is in agreement with these findings. Additional reports identifying OH-BDEs in polar bears are not available and it remains to be determined if the other metabolites of BDE-47 or BDE-99 quantified in our study are produced in vivo. We were unable to determine whether 
the parent compounds, BDE-47 and BDE-99, were present in the polar bear liver microsomes because the UHPLC/MS/MS methods we used are not suitable for detecting non-hydroxylated PBDEs. Thus, we cannot confirm that the polar bears used in the present study were environmentally exposed to PBDEs in vivo. However, PBDEs including BDE-47 and BDE-99 were detected in adipose tissue collected from polar bears from the western Hudson Bay region of Canada during the period from 1991 to 2007 (McKinney et al., 2010), which overlaps the collection period in our study (i.e., 1992-1994) and suggests it is likely that the polar bears used herein were environmentally exposed to PBDEs in vivo.

Oxidative biotransformation of BDE-47 and BDE-99 has toxicological relevance because many of the OH-BDE metabolites identified in the current study have been found to have greater biological activity than the parent compounds. For example, 4-OH-BDE-42, 5-OH-BDE-47, 6OH-BDE-47 and 4'-OH-BDE-49 bind to human and rat transthyretin, the thyroid hormone transport protein, and displace thyroxine binding more effectively than BDE-47 (Hamers et al., 2006; Hamers et al., 2008; Marchesini et al., 2008; Cao et al., 2010; Ren and Guo, 2012). Among the hydroxylated metabolites of BDE-99, 6'-OH-BDE-99 inhibits thyroxine binding to transthyretin and 5'-OH-BDE-99 inhibits 3,3',5-triiodothyronine formation by human liver microsomes more effectively than BDE-99 (Marchesini et al., 2008; Butt et al., 2011). In addition to disruption of thyroid homeostasis, 4'-OH-BDE-49, 5-OH-BDE-47 and 6-OH-BDE-47 have been reported to alter cellular calcium homeostasis in rat adrenal tumor cells (Dingemans et al., 2010) and 4'-OH-BDE-17, 2'-OH-BDE-28, 5-OH-BDE-47 and 6-OH-BDE-47 were shown to disrupt mitochondrial oxidative phosphorylation in vitro (Legradi et al., 2014). In vivo exposure to 5-OH-BDE-47 and 6-OH-BDE-47 in zebrafish produced concentration-dependent mortality and delayed development along with cell death and oxidative stress, while exposure to BDE-47 
did not (Usenko et al., 2012). Taken together, the studies demonstrate that many of the hydroxylated metabolites of BDE-47 and BDE-99 formed by the polar bear liver microsomes are capable of eliciting toxic effects.

In conclusion, the present study demonstrated that polar bears are capable of oxidatively biotransforming PBDEs and producing multiple hydroxylated metabolites of BDE-47 and BDE99. CYP2B was found to be the most active CYP enzyme in the biotransformation of BDE-47 and BDE-99. An implication of the study is that, although some of the OH-BDEs detected in polar bear tissue could originate from the diet (i.e. consumption of seals), OH-BDEs are also formed through PBDE metabolism in vivo. The study also demonstrated that archived liver microsomes that have been stored in a manner that preserves catalytic activity are useful for assessing in vitro biotransformation in wildlife species and can provide valuable information about metabolite profiles, especially if fresh liver tissue is difficult to obtain.

\section{Acknowledgements}

We thank Dr. Robert J. Letcher, Environment Canada, for providing the 2-OH-BDE-123 standard.

\section{Funding}

Funding for the study was received from the Natural Sciences and Engineering Research Council of Canada (RGPIN 138733-10 to SMB).

\section{Conflict of interests}

The authors declare that there is no conflict of interest. 


\section{References}

Alaee, M., Arias, P., Sjodin, A., Bergman, A., 2003. An overview of commercially used brominated flame retardants, their applications, their use patterns in different countries/regions and possible modes of release. Environment international 29, 683-689.

Anderson, M.D., Bandiera, S.M., Chang, T.K., Bellward, G.D., 1998. Effect of androgen administration during puberty on hepatic CYP2C11, CYP3A, and CYP2A1 expression in adult female rats. Drug metabolism and disposition: the biological fate of chemicals 26, 1031-1038.

Bandiera, S.M., Torok, S.M., Lin, S., Ramsay, M.A., Norstrom, R.J., 1995. Catalytic and immunologic characterization of hepatic and lung cytochromes P450 in the polar bear. Biochemical pharmacology 49, 1135-1146.

Besis, A., Samara, C., 2012. Polybrominated diphenyl ethers (PBDEs) in the indoor and outdoor environments--a review on occurrence and human exposure. Environmental pollution (Barking, Essex : 1987) 169, 217-229.

Branchi, I., Capone, F., Alleva, E., Costa, L.G., 2003. Polybrominated diphenyl ethers: neurobehavioral effects following developmental exposure. Neurotoxicology 24, 449-462.

Butt, C.M., Wang, D., Stapleton, H.M., 2011. Halogenated phenolic contaminants inhibit the in vitro activity of the thyroid-regulating deiodinases in human liver. Toxicological sciences : an official journal of the Society of Toxicology 124, 339-347.

Cao, J., Lin, Y., Guo, L.H., Zhang, A.Q., Wei, Y., Yang, Y., 2010. Structure-based investigation on the binding interaction of hydroxylated polybrominated diphenyl ethers with thyroxine transport proteins. Toxicology 277, 20-28.

Cheng, J., Gu, J., Ma, J., Chen, X., Zhang, M., Wang, W., 2009. Neurobehavioural effects, redox responses and tissue distribution in rat offspring developmental exposure to BDE-99. Chemosphere 75, 963-968.

Chu, S., Letcher, R.J., 2013. Halogenated phenolic compound determination in plasma and serum by solid phase extraction, dansylation derivatization and liquid chromatography-positive electrospray ionization-tandem quadrupole mass spectrometry. Journal of chromatography. A 1320, 111-117.

Daniels, J.L., Pan, I.J., Jones, R., Anderson, S., Patterson, D.G., Jr., Needham, L.L., Sjodin, A., 2010. Individual characteristics associated with PBDE levels in U.S. human milk samples. Environmental health perspectives $118,155-160$.

de Wit, C.A., Alaee, M., Muir, D.C., 2006. Levels and trends of brominated flame retardants in the Arctic. Chemosphere 64, 209-233.

de Wit, C.A., Herzke, D., Vorkamp, K., 2010. Brominated flame retardants in the Arctic environment-trends and new candidates. The Science of the total environment 408, 2885-2918.

Dietz, R., Riget, F.F., Sonne, C., Born, E.W., Bechshoft, T., McKinney, M.A., Drimmie, R.J., Muir, D.C., Letcher, R.J., 2013. Three decades (1983-2010) of contaminant trends in East Greenland polar bears (Ursus maritimus). Part 2: brominated flame retardants. Environment international 59, 494-500.

Dingemans, M.M., Heusinkveld, H.J., Bergman, A., van den Berg, M., Westerink, R.H., 2010. Bromination pattern of hydroxylated metabolites of BDE-47 affects their potency to release calcium from intracellular stores in PC12 cells. Environmental health perspectives 118, 519-525.

Dong, H., Li, Z., Man, X., Zhou, J., Lu, H., Wang, S., 2010. Identification of the metabolites of polybrominated diphenyl ether 99 and its related cytochrome P450s. Journal of biomedical research 24, 223-232. 
Ekins, S., Vandenbranden, M., Ring, B.J., Gillespie, J.S., Yang, T.J., Gelboin, H.V., Wrighton, S.A., 1998. Further characterization of the expression in liver and catalytic activity of CYP2B6. The Journal of pharmacology and experimental therapeutics 286, 1253-1259.

Erratico, C.A., Moffatt, S.C., Bandiera, S.M., 2011. Comparative oxidative metabolism of BDE-47 and BDE-99 by rat hepatic microsomes. Toxicological sciences : an official journal of the Society of Toxicology 123, 37-47.

Erratico, C.A., Szeitz, A., Bandiera, S.M., 2010. Validation of a novel in vitro assay using ultra performance liquid chromatography-mass spectrometry (UPLC/MS) to detect and quantify hydroxylated metabolites of BDE-99 in rat liver microsomes. Journal of chromatography. B, Analytical technologies in the biomedical and life sciences 878, 1562-1568.

Erratico, C.A., Szeitz, A., Bandiera, S.M., 2012. Oxidative metabolism of BDE-99 by human liver microsomes: predominant role of CYP2B6. Toxicological sciences : an official journal of the Society of Toxicology 129, 280-292.

Erratico, C.A., Szeitz, A., Bandiera, S.M., 2013. Biotransformation of 2,2',4,4'-tetrabromodiphenyl ether (BDE-47) by human liver microsomes: identification of cytochrome P450 2B6 as the major enzyme involved. Chemical research in toxicology 26, 721-731.

Feo, M.L., Gross, M.S., McGarrigle, B.P., Eljarrat, E., Barcelo, D., Aga, D.S., Olson, J.R., 2013. Biotransformation of BDE-47 to potentially toxic metabolites is predominantly mediated by human CYP2B6. Environmental health perspectives 121, 440-446.

Gebbink, W.A., Sonne, C., Dietz, R., Kirkegaard, M., Riget, F.F., Born, E.W., Muir, D.C., Letcher, R.J., 2008. Tissue-specific congener composition of organohalogen and metabolite contaminants in East Greenland polar bears (Ursus maritimus). Environmental pollution (Barking, Essex : 1987) 152, 621-629.

Gee, J.R., Moser, V.C., 2008. Acute postnatal exposure to brominated diphenylether 47 delays neuromotor ontogeny and alters motor activity in mice. Neurotoxicology and teratology 30, 79-87.

Gewurtz, S.B., McGoldrick, D.J., Clark, M.G., Keir, M.J., Malecki, M.M., Gledhill, M., Sekela, M., Syrgiannis, J., Evans, M.S., Armellin, A., Pomeroy, J., Waltho, J., Backus, S.M., 2011. Spatial trends of polybrominated diphenyl ethers in Canadian fish and implications for long-term monitoring. Environmental toxicology and chemistry / SETAC 30, 1564-1575.

Gomara, B., Herrero, L., Ramos, J.J., Mateo, J.R., Fernandez, M.A., Garcia, J.F., Gonzalez, M.J., 2007. Distribution of polybrominated diphenyl ethers in human umbilical cord serum, paternal serum, maternal serum, placentas, and breast milk from Madrid population, Spain. Environmental science \& technology 41, 6961-6968.

Hale, R.C., La Guardia, M.J., Harvey, E.P., Mainor, T.M., Duff, W.H., Gaylor, M.O., 2001. Polybrominated diphenyl ether flame retardants in Virginia freshwater fishes (USA). Environmental science \& technology 35, 4585-4591.

Hallgren, S., Sinjari, T., Hakansson, H., Darnerud, P.O., 2001. Effects of polybrominated diphenyl ethers (PBDEs) and polychlorinated biphenyls (PCBs) on thyroid hormone and vitamin A levels in rats and mice. Archives of toxicology 75, 200-208.

Hamers, T., Kamstra, J.H., Sonneveld, E., Murk, A.J., Kester, M.H., Andersson, P.L., Legler, J., Brouwer, A., 2006. In vitro profiling of the endocrine-disrupting potency of brominated flame retardants. Toxicological sciences : an official journal of the Society of Toxicology 92, 157-173.

Hamers, T., Kamstra, J.H., Sonneveld, E., Murk, A.J., Visser, T.J., Van Velzen, M.J., Brouwer, A., Bergman, A., 2008. Biotransformation of brominated flame retardants into potentially endocrine-disrupting metabolites, with special attention to 2,2',4,4'-tetrabromodiphenyl ether (BDE-47). Molecular nutrition \& food research 52, 284-298.

Hites, R.A., 2004. Polybrominated diphenyl ethers in the environment and in people: a meta-analysis of concentrations. Environmental science \& technology 38, 945-956. 
Hrycay, E.G., Bandiera, S.M., 2003. Spectral interactions of tetrachlorobiphenyls with hepatic microsomal cytochrome p450 enzymes. Chemico-biological interactions 146, 285-296.

Ikonomou, M.G., Rayne, S., Addison, R.F., 2002. Exponential increases of the brominated flame retardants, polybrominated diphenyl ethers, in the Canadian Arctic from 1981 to 2000. Environmental science \& technology 36, 1886-1892.

Kelly, B.C., Ikonomou, M.G., Blair, J.D., Gobas, F.A., 2008. Bioaccumulation behaviour of polybrominated diphenyl ethers (PBDEs) in a Canadian Arctic marine food web. The Science of the total environment 401, 60-72.

Kodavanti, P.R., Coburn, C.G., Moser, V.C., MacPhail, R.C., Fenton, S.E., Stoker, T.E., Rayner, J.L., Kannan, K., Birnbaum, L.S., 2010. Developmental exposure to a commercial PBDE mixture, DE-71: neurobehavioral, hormonal, and reproductive effects. Toxicological sciences : an official journal of the Society of Toxicology 116, 297-312.

Kodavanti, P.R., Royland, J.E., Osorio, C., Winnik, W.M., Ortiz, P., Lei, L., Ramabhadran, R., Alzate, O., 2015. Developmental exposure to a commercial PBDE mixture: effects on protein networks in the cerebellum and hippocampus of rats. Environmental health perspectives 123, 428-436.

Kuriyama, S.N., Talsness, C.E., Grote, K., Chahoud, I., 2005. Developmental exposure to low dose PBDE 99: effects on male fertility and neurobehavior in rat offspring. Environmental health perspectives 113, 149-154.

La Guardia, M.J., Hale, R.C., Harvey, E., 2006. Detailed polybrominated diphenyl ether (PBDE) congener composition of the widely used penta-, octa-, and deca-PBDE technical flame-retardant mixtures. Environmental science \& technology 40, 6247-6254.

Law, R.J., Covaci, A., Harrad, S., Herzke, D., Abdallah, M.A., Fernie, K., Toms, L.M., Takigami, H., 2014. Levels and trends of PBDEs and HBCDs in the global environment: status at the end of 2012. Environment international 65, 147-158.

Legradi, J., Dahlberg, A.K., Cenijn, P., Marsh, G., Asplund, L., Bergman, A., Legler, J., 2014. Disruption of oxidative phosphorylation (OXPHOS) by hydroxylated polybrominated diphenyl ethers (OH-PBDEs) present in the marine environment. Environmental science \& technology 48, 14703-14711.

Letcher, R.J., Bustnes, J.O., Dietz, R., Jenssen, B.M., Jorgensen, E.H., Sonne, C., Verreault, J., Vijayan, M.M., Gabrielsen, G.W., 2010. Exposure and effects assessment of persistent organohalogen contaminants in arctic wildlife and fish. The Science of the total environment 408, 2995-3043.

Letcher, R.J., Gebbink, W.A., Sonne, C., Born, E.W., McKinney, M.A., Dietz, R., 2009. Bioaccumulation and biotransformation of brominated and chlorinated contaminants and their metabolites in ringed seals (Pusa hispida) and polar bears (Ursus maritimus) from East Greenland. Environment international 35, 1118-1124.

Letcher, R.J., Norstrom, R.J., Lin, S., Ramsay, M.A., Bandiera, S.M., 1996. Immunoquantitation and microsomal monooxygenase activities of hepatic cytochromes P4501A and P4502B and chlorinated hydrocarbon contaminant levels in polar bear (Ursus maritimus). Toxicology and applied pharmacology 137, 127-140.

Lilienthal, H., Hack, A., Roth-Harer, A., Grande, S.W., Talsness, C.E., 2006. Effects of developmental exposure to $2,2,4,4,5$-pentabromodiphenyl ether (PBDE-99) on sex steroids, sexual development, and sexually dimorphic behavior in rats. Environmental health perspectives 114, 194-201.

Malmvarn, A., Zebuhr, Y., Kautsky, L., Bergman, K., Asplund, L., 2008. Hydroxylated and methoxylated polybrominated diphenyl ethers and polybrominated dibenzo-p-dioxins in red alga and cyanobacteria living in the Baltic Sea. Chemosphere 72, 910-916.

Marchesini, G.R., Meimaridou, A., Haasnoot, W., Meulenberg, E., Albertus, F., Mizuguchi, M., Takeuchi, M., Irth, H., Murk, A.J., 2008. Biosensor discovery of thyroxine transport disrupting chemicals. Toxicology and applied pharmacology 232, 150-160. 
McKinney, M.A., De Guise, S., Martineau, D., Beland, P., Arukwe, A., Letcher, R.J., 2006. Biotransformation of polybrominated diphenyl ethers and polychlorinated biphenyls in beluga whale (Delphinapterus leucas) and rat mammalian model using an in vitro hepatic microsomal assay. Aquatic toxicology (Amsterdam, Netherlands) 77, 87-97.

McKinney, M.A., Dietz, R., Sonne, C., De Guise, S., Skirnisson, K., Karlsson, K., Steingrimsson, E., Letcher, R.J., 2011. Comparative hepatic microsomal biotransformation of selected PBDEs, including decabromodiphenyl ether, and decabromodiphenyl ethane flame retardants in Arctic marine-feeding mammals. Environmental toxicology and chemistry / SETAC 30, 1506-1514.

McKinney, M.A., Iverson, S.J., Fisk, A.T., Sonne, C., Riget, F.F., Letcher, R.J., Arts, M.T., Born, E.W., RosingAsvid, A., Dietz, R., 2013. Global change effects on the long-term feeding ecology and contaminant exposures of East Greenland polar bears. Global change biology 19, 2360-2372.

McKinney, M.A., Pedro, S., Dietz, R., Sonne, C., Fisk, A.T., Roy, D., Jenssen, B.M., Letcher, R.J., 2015. A review of ecological impacts of global climate change on persistent organic pollutant and mercury pathways and exposures in arctic marine ecosystems. Current zoology 61, 617-628.

McKinney, M.A., Stirling, I., Lunn, N.J., Peacock, E., Letcher, R.J., 2010. The role of diet on long-term concentration and pattern trends of brominated and chlorinated contaminants in western Hudson Bay polar bears, 1991-2007. The Science of the total environment 408, 6210-6222.

Moffatt, S.C., Edwards, P.R., Szeitz, A., Bandiera, S.M., 2011. A Validated Liquid Chromatography-Mass Spectrometry Method for the Detection and Quantification of Oxidative Metabolites of 2,2',4,4'Tetrabromodiphenyl Ether in Rat Hepatic Microsomes. American Journal of Analytical Chemistry 2, 352362.

Quiros-Alcala, L., Bradman, A., Nishioka, M., Harnly, M.E., Hubbard, A., McKone, T.E., Eskenazi, B., 2011. Concentrations and loadings of polybrominated diphenyl ethers in dust from low-income households in California. Environment international 37, 592-596.

Ren, X.M., Guo, L.H., 2012. Assessment of the binding of hydroxylated polybrominated diphenyl ethers to thyroid hormone transport proteins using a site-specific fluorescence probe. Environmental science \& technology 46, 4633-4640.

Rotander, A., van Bavel, B., Polder, A., Riget, F., Auethunsson, G.A., Gabrielsen, G.W., Vikingsson, G., Bloch, D., Dam, M., 2012. Polybrominated diphenyl ethers (PBDEs) in marine mammals from Arctic and North Atlantic regions, 1986-2009. Environment international 40, 102-109.

Routti, H., Letcher, R.J., Chu, S., Van Bavel, B., Gabrielsen, G.W., 2009. Polybrominated diphenyl ethers and their hydroxylated analogues in ringed seals (Phoca hispida) from Svalbard and the Baltic Sea. Environmental science \& technology 43, 3494-3499.

Sjodin, A., Wong, L.Y., Jones, R.S., Park, A., Zhang, Y., Hodge, C., Dipietro, E., McClure, C., Turner, W., Needham, L.L., Patterson, D.G., Jr., 2008. Serum concentrations of polybrominated diphenyl ethers (PBDEs) and polybrominated biphenyl (PBB) in the United States population: 2003-2004. Environmental science \& technology 42, 1377-1384.

Stapleton, H.M., Dodder, N.G., Offenberg, J.H., Schantz, M.M., Wise, S.A., 2005. Polybrominated diphenyl ethers in house dust and clothes dryer lint. Environmental science \& technology 39, 925-931.

Talsness, C.E., Kuriyama, S.N., Sterner-Kock, A., Schnitker, P., Grande, S.W., Shakibaei, M., Andrade, A., Grote, K., Chahoud, I., 2008. In utero and lactational exposures to low doses of polybrominated diphenyl ether-47 alter the reproductive system and thyroid gland of female rat offspring. Environmental health perspectives 116, 308-314.

Usenko, C.Y., Hopkins, D.C., Trumble, S.J., Bruce, E.D., 2012. Hydroxylated PBDEs induce developmental arrest in zebrafish. Toxicology and applied pharmacology 262, 43-51.

Verreault, J., Gabrielsen, G.W., Chu, S., Muir, D.C., Andersen, M., Hamaed, A., Letcher, R.J., 2005. Flame retardants and methoxylated and hydroxylated polybrominated diphenyl ethers in two Norwegian Arctic top predators: glaucous gulls and polar bears. Environmental science \& technology 39, 6021-6028. 
Wong, A., Bandiera, S.M., 1996. Inductive effect of Telazol on hepatic expression of cytochrome P450 2B in rats. Biochemical pharmacology 52, 735-742.

Zhou, T., Ross, D.G., DeVito, M.J., Crofton, K.M., 2001. Effects of short-term in vivo exposure to polybrominated diphenyl ethers on thyroid hormones and hepatic enzyme activities in weanling rats. Toxicological sciences : an official journal of the Society of Toxicology 61, 76-82. 
Marsh, G., Athanasiadou, M., Athanassiadis, X.J. Sandholm, A. 2006. Identification of hydroxylated metabolites in 2,2',4,4'-tetrabromodiphenyl ether exposed rats. Chemosphere 63, 690-697.

\section{Figure captions}

Fig. 1. Representative UHPLC/MS/MS chromatograms of the hydroxylated metabolites of BDE47 formed by polar bear liver microsomes. Hepatic microsomes (1 mg mL-1) were incubated with BDE-47 $(100 \mu \mathrm{M})$ for 20 min. Chromatograms showing the TIC of the MRM transitions in negative ionization mode of monoOH-tetraBDE metabolites (panel A), diOH-tetraBDE metabolites (panel B), monoOH-triBDE metabolites (panel C) and the dibromophenol metabolite (2,4-DBP) (panel D) are presented. A peak corresponding to 2,4-DBP was present in control samples in which BDE-47 or NADPH was omitted from the reaction mixture.

Fig. 2. Representative UHPLC/MS/MS chromatograms of the hydroxylated metabolites of BDE99 formed by polar bear liver microsomes. Hepatic microsomes $(1 \mathrm{mg} \mathrm{mL}-1)$ were incubated with BDE-99 $(100 \mu \mathrm{M})$ for 20 min. Chromatograms showing the TIC of the MRM transitions in negative ionization mode of monoOH-pentaBDE metabolites (panel A), diOH-pentaBDE metabolites (panel B), the tribromophenol metabolite (2,4,5-TBP) (panel C) and the dibromophenol metabolite (2,4-DBP) (panel D) are presented. A peak corresponding to 2,4-DBP was present in control samples in which BDE-99 or NADPH was omitted from the reaction mixture. 


\section{Table 1}

Rates of formation of known hydroxylated metabolites of BDE-47 by polar bear liver microsomes.

\begin{tabular}{|c|c|c|c|c|c|c|c|}
\hline \multirow{2}{*}{$\begin{array}{l}\text { Polar } \\
\text { bear } \\
(n=15)\end{array}$} & \multicolumn{7}{|c|}{ Rates of metabolite formation (pmol metabolite mg-1 protein min-1) } \\
\hline & 3'-OH-BDE-28 & 4'-OH-BDE-17 & 2'-OH-BDE-28 & 4-OH-BDE-42 & 5-OH-BDE-47 & 4'-OH-BDE-49 & 6-OH-BDE-47 \\
\hline Mean $( \pm$ SEM $)$ & $1.54( \pm 0.06)$ & $0.82( \pm 0.07)$ & $0.19( \pm 0.01)$ & $0.88( \pm 0.06)$ & $1.93( \pm 0.16)$ & $2.81( \pm 0.18)$ & $1.39( \pm 0.11)$ \\
\hline Range & $1.23-2.33$ & $0.43-1.31$ & $0.10-0.28$ & $0.57-1.28$ & $1.00-3.00$ & $1.44-4.34$ & $0.67-2.13$ \\
\hline
\end{tabular}

Mean ( \pm SEM) values were calculated from individual data of 15 polar bear samples. The range represents the smallest and greatest rates of formation of the metabolites. Polar bear liver microsomes (1 mg mL-1) were incubated with BDE-47 (100 $\mu$ M) and NADPH (1 mM) for 20 min. 


\section{Table 2}

Rates of formation of unknown metabolites of BDE-47 by polar bear liver microsomes.

\begin{tabular}{llll}
\hline \multirow{2}{*}{$\begin{array}{l}\text { Polar } \\
\text { bear } \\
(\mathrm{n}=15)\end{array}$} & \multicolumn{3}{c}{ Rates of metabolite formation (response $\times 10^{-2}$ mg-1 protein min-1) } \\
\cline { 2 - 4 } Mean $( \pm$ SEM) & $0.98( \pm 0.07)$ & $3.16( \pm 0.23)$ & $\mathrm{C}$ \\
\hline Range & $0.50-1.33$ & $1.50-4.33$ & $0.98( \pm 0.13)$ \\
& & & $0.50-2.00$ \\
\hline
\end{tabular}

Values are expressed as the response $\times 10^{-2} \mathrm{mg}-1$ protein min-1, where response is defined as peak area count of the metabolite/peak area count of the internal standard.

Mean ( \pm SEM) values were calculated from individual data of 15 polar bear samples. The range represents the smallest and greatest rates of formation of the metabolites. 


\section{Table 3}

Rates of formation of known hydroxylated metabolites of BDE-99 by polar bear liver microsomes.

\begin{tabular}{|c|c|c|c|c|c|}
\hline \multirow{2}{*}{$\begin{array}{l}\text { Polar } \\
\text { bear } \\
(n=15)\end{array}$} & \multicolumn{5}{|c|}{ Rates of metabolite formation (pmol metabolite mg-1 protein min-1) } \\
\hline & 2,4,5-TBP & 4-OH-BDE-90 & 5'-OH-BDE-99 & 6'-OH-BDE-99 & 4'-OH-BDE-101 \\
\hline Mean $( \pm$ SEM $)$ & $3.41( \pm 0.36)$ & $1.64( \pm 0.20)$ & $0.75( \pm 0.07)$ & $0.11( \pm 0.03)$ & $0.21( \pm 0.04)$ \\
\hline Range & $0.87-6.17$ & $0.48-3.57$ & $0.33-1.38$ & $<0.125^{*}-0.43$ & $<0.125^{*}-0.55$ \\
\hline
\end{tabular}

Mean ( \pm SEM) values were calculated from individual data of 15 polar bear samples. The range represents the smallest and greatest rates of formation of the metabolites. Polar bear liver microsomes (1 mg mL-1) were incubated with BDE-99 (100 $\mu$ M) and NADPH (1 mM) for 20 min.

* The lower limit of quantification, as determined from the calibration curves was $2.5 \mathrm{nM}$ (see Supplementary material), which is expressed, in terms of rate of metabolite formation, as $0.125 \mathrm{pmol} \mathrm{mg-1}$ protein min-1 for 6'-OH-BDE-99 and 4'-OH-BDE-101. 


\section{Table 4}

Rates of formation of unknown metabolites of BDE-99 by polar bear liver microsomes.

\begin{tabular}{lllll}
\hline $\begin{array}{l}\text { Polar } \\
\text { bear } \\
(\mathrm{n}=15)\end{array}$ & \multicolumn{4}{c}{ Rates of metabolite formation (response $\times 10^{-2}$ mg-1 protein min- $)$} \\
\cline { 2 - 5 } & $\mathrm{D}$ & $\mathrm{E}$ & $\mathrm{F}$ & $\mathrm{G}$ \\
\hline Mean $( \pm$ SEM) & $7.31( \pm 0.61)$ & $7.29( \pm 0.82)$ & $3.39( \pm 0.75)$ & $11.78( \pm 1.29)$ \\
Range & $4.00-14.00$ & $3.67-17.00$ & $1.89-5.76$ & $5.00-20.30$ \\
\hline
\end{tabular}

Values are expressed as the response $\times 10^{-2} \mathrm{mg}-1$ protein min-1, where response is defined as peak area count of the metabolite/peak area count of the internal standard.

Mean ( \pm SEM) values were calculated from individual data of 15 polar bear samples. The range represents the smallest and greatest rates of formation of the metabolites. 


\section{Table 5}

Rates of formation of the monoOH-triBDE and monoOH-tetraBDE metabolites of BDE-99 by a subset polar bear liver microsomes.

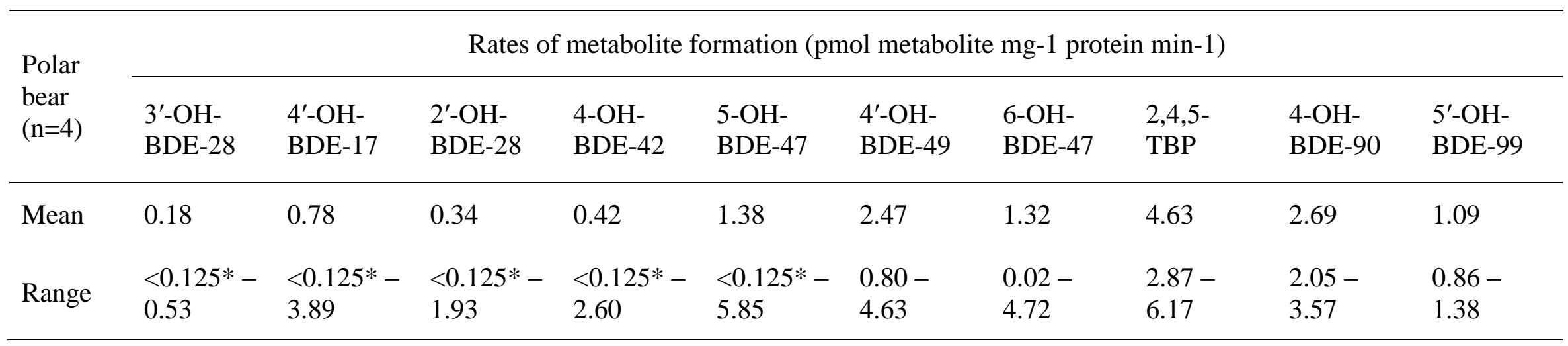

Mean values were calculated from individual data of four polar bear liver microsomes. These four polar bear samples were determined to be more catalytically active than the remaining polar bear samples. The range represents the smallest and greatest rates of formation of the metabolites. A new unidentified monoOH-tetraBDE metabolite of BDE-99, labelled as H, was also detected. This metabolite was not produced when BDE-47 was the substrate. Rates of formation of 2,4,5-TBP, 4-OH-BDE-90 and 5'-OH-BDE-99 are included to provide a more complete summary of metabolite formation among the four polar bear samples.

* The lower limit of quantification, as determined from the calibration curves was $2.5 \mathrm{nM}$ (see Supplementary material), which is expressed, in terms of rate of metabolite formation, as 0.125 pmol mg-1 protein min-1 for 3'-OH-BDE-28, 4'-OH-BDE-17, 2'-OH-BDE-28 and 4-OH-BDE-42. 
A TIC of-MRMs of monoOH-tetraBDEs

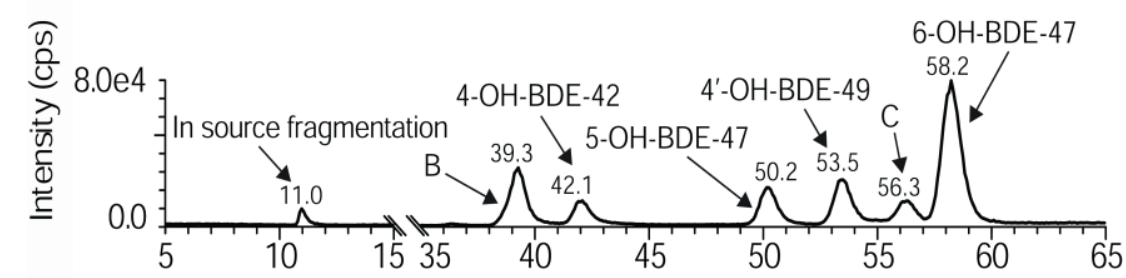

B TIC of -MRMs of diOH-tetraBDEs

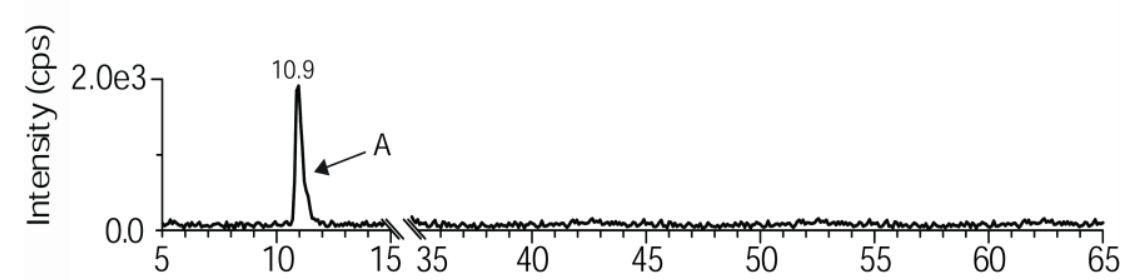

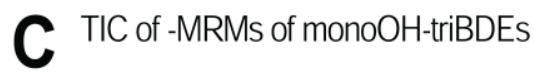

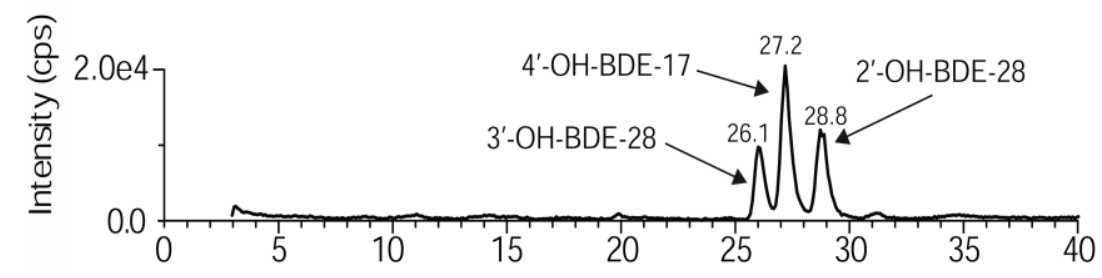

D TIC of -MRMs of 2,4-DBP

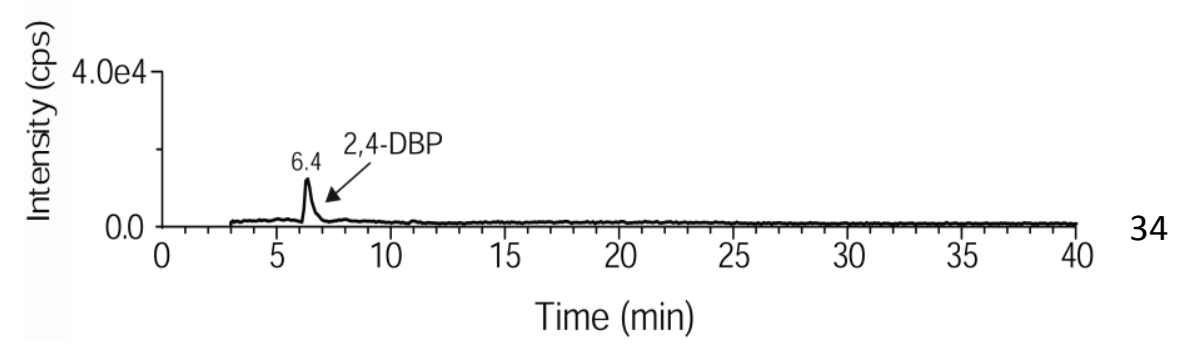

Fig. 1. 


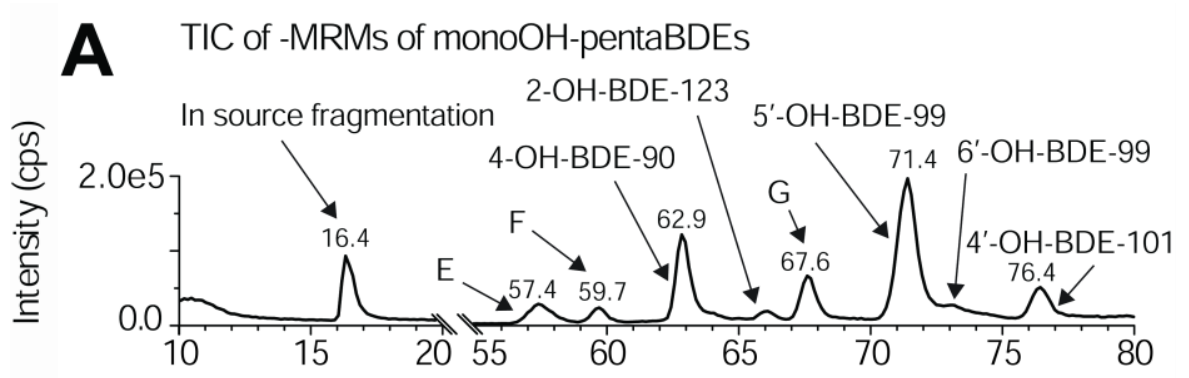

B TIC of -MRMs of diOH-pentaBDEs

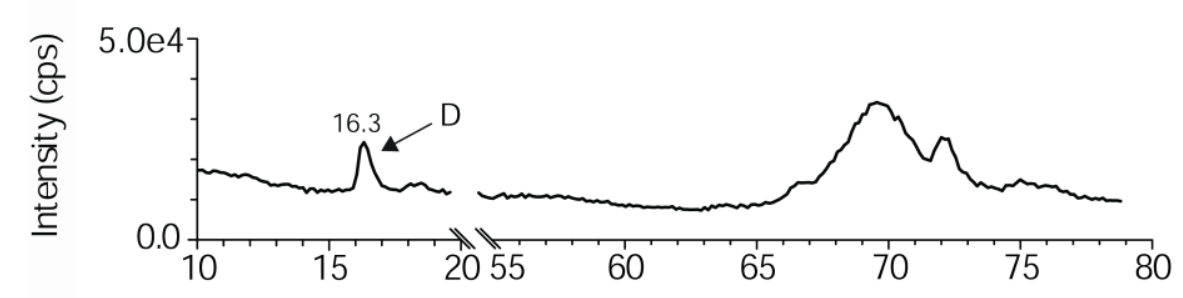

C TIC of -MRMs of 2,4,5-TBP

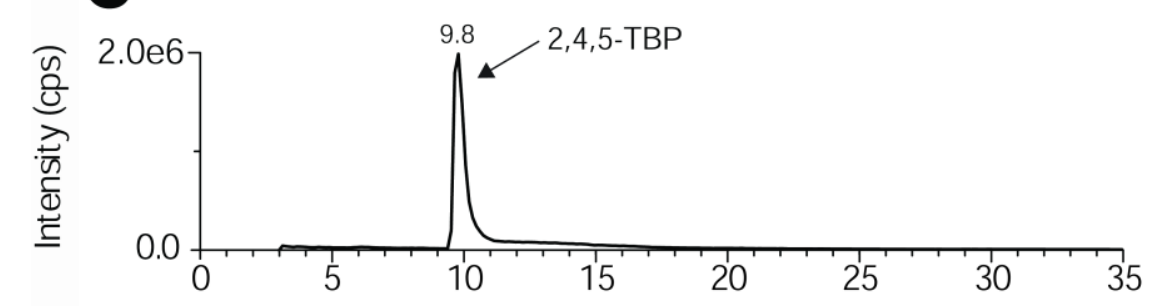

\section{TIC of -MRMs of 2,4-DBP}

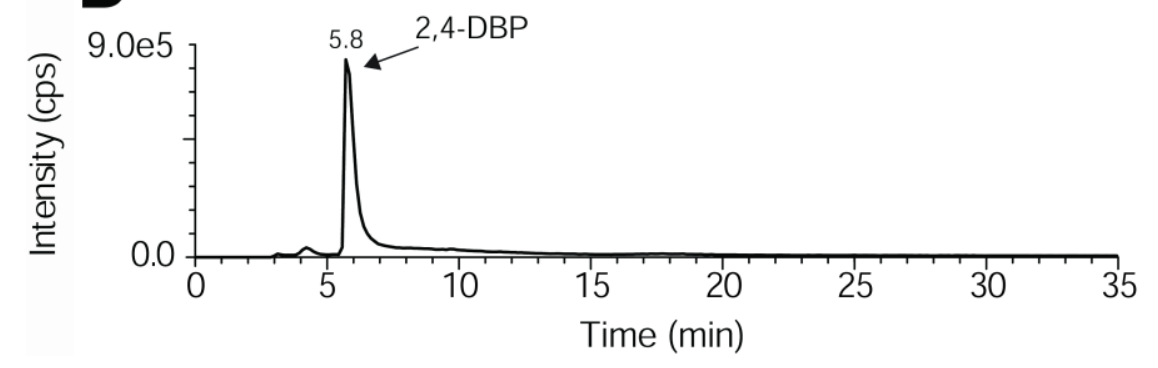

Fig. 2. 
